\title{
Estudios comparativos en la versología
}

\author{
LADISLAV FRANEK
}

\begin{abstract}
Comparative research in versology. The place of comparative literature in Slovak literary studies from the 1960s. Mikuláš Bakošs inspiration by the model of historical poetics in his writing on the Slovak verse in the late 1930s. The influence of Russian formalism and Czech structuralism (J. Mukařovský, J. Levý). The focus on the stylistic and typological aspect in verse analysis. The effort towards the symbiosis of the structuraldevelopmental and the traditional historical-critical approaches. The inspiration by Jozef Felix's emphasis on the universal message of the finest French and world literature for the development of Slovak literature. The contribution of the theory of literary communication for the analysis of Slovak reception of translations from Russian literature (A. Popovič). The re-evaluation of the term "influence" on the basis of a dialectical understanding of the roles of comparative literature (D. Durišin). The aspect of the developmental progress of national literatures. The central role of poetic rhythm through the specific application of metric accent in comparing Slovak verse with French and Spanish verse (L. Franek). The meaning of comparative study of poetry in symbiosis with objective-normative and subjective-critical criteria in relation to aesthetic level of translations. The unity of theoretical and empirical research as a reliable instrument in contemporary search for literary and cultural identity of nations (Slovak translations of Paul Claudel).
\end{abstract}

Keywords: comparative versology; Mikuláš Bakoš; Jozef Felix; Anton Popovič; Dionýz Ďurišin; Ladislav Franek; Slovakian literary scholarship

Acaso no es inútil recordar que los estudios comparativos de literatura se caracterizan por una variedad de aspectos históricos y teóricos que se necesitan para alcanzar, según la materia analizada, los fines interdisciplinares, sintéticos. Por consiguiente, antes de mi intento ilustrativo más concreto quisiera prestar mayor atención, al menos en unos puntos esenciales, a los resultados múltiples que fueron realizados, ante todo en los años 60 y a principios de los 70 en las áreas de la teoría y la historia literaria eslovaca. Mi interés se dirige en la segunda parte a la confrontación del verso eslovaco con el verso de literaturas romances (el francés, el español). Por esa razón intento seguir esa problemática en relación con al desarrollo específico del pensamiento eslovaco en torno a esa disciplina. No es sin interés observar que para definirla suficientemente hay que tener en cuenta varios factores que, en conjunto, contribuyeron en

DOI: https://doi.org/10.12697/IL.2018.23.2.3 
Eslovaquia al nacimiento de varios paradigmas específicos. Ya que casi todos ellos se propusieron ver los fenómenos estudiados en relaciones o correlaciones más amplias. Pues ese propósito no es nada fortuito siendo guiado por el deseo de sobrepasar el espacio de la literatura nacional hacia los horizontes supranacionales de literatura.

Digámonos en primer lugar que en las condiciones de Eslovaquia, de una nación pequeña, existiendo en el pasado no tan lejano con otra nación más grande dentro del país llamado Checoslovaquia y situada en el cruce de varias culturas, se trazaba ya entonces la posibilidad de explotar una suma de impulsos variados para la aplicación auténtica y, en cierto modo, original de la literatura comparada.

El primer hito en la época moderna fue el aňo 1964, año de la fundación del Instituto de literatura e idiomas extranjeros de la Academia eslovaca de ciencias en Bratislava. El mérito principal en ese evento pertenece, sin duda, a Mikuláš Bakoš quien, por su erudición, era bien familiarizado con la riqueza de los trabajos europeos, sobre todo en la linguística y la teoría literaria moderna. El primer objetivo, claramente colectivo de Bakoš, era abordar a la generación jóven de científicos eslovacos para hacer del estudio literario una disciplina relativamente autónoma, con su propios métodos e instrumentos que hubieran sido independientes del método de otras diciplinas científicas. Para conseguir esa meta el interés se centraba en el hecho literario que tuviera que ser estudiado de modo racional, lógicamente analizable y verificable. De tal modo se abría el espacio nuevo, desarrollado sobre una base dinámica y procesal, para el área de la literatura comparada.

Bajo la influencia del formalismo ruso y del método estructural del checo Jan Mukařovský ha tenido Bakoš la intención de reanimar su modelo teórico que a finales de los años 30 él mismo aplicó en el estudio sistemático de la evolución del verso eslovaco (véanse Bakoš 1968 - La evolución del verso eslovaco desde la generación Štúr, 1939, 1949, 1966). Su método intraliterario fue fundado en la unión de la teoría y la poética histórica lo cual era una novedad radical por estudiar formas variables del verso eslovaco en el curso de su historia. Una interdependencia dinámica de esas formas Bakoš la veía en el estudio fónico, tónico, sintáctico, semántico y métrico, de todos los elementos en la estructura del verso. Ésos han presentado en su concepción un movimiento permanente de intercambios o alternancias. Igual que Mukařovský, aunque de modo diferente, más formal y procesal, subrayaba Bakoš el papel primordial del ritmo poético cuya función dependía de la primacía de tal o tal componente en la evolución poética de la generación romántica, simbólica y postsimbólica. Se trataba pues de un modelo racional y lógico siguiendo fielmente los principios vanguardistas, procedentes en Eslovaquia de la época de entre dos guerras. 
El objeto principal era la materia misma del quehacer poético, suficientemente definido y demostrado por vía estadística. En el espíritu del optimismo epistemológico, que reinaba en esos tiempos relativamente libres de investigación, se desarrolaba al mismo tiempo una cooperación fertil con los científicos polacos, soviéticos, checos y de otros países socialistas. El punto común de esas actividades internacionales era el intento de llegar a una síntesis artísticocientífica.

Es evidente que en los años 60 cuando fue fundado el Instituto haya tenido Bakoš, su director, la ambición de ampliar el estudio de la literatura eslovaca nacional y de integrarla gradualmente en el área interliteraria. De tal manera hizo el primer paso al enlazar con su trabajos anteriores para que se pueda realizar en el porvenir con éxito su proyecto multilateral.

A pesar de muchos obstáculos y limitaciones externas, ideológico-políticas, con orgullo y modestía de una persona carismática, el científico eslovaco trataba de desenvolver y realizar el método tipológico de literatura. La amplitud de sus actividades científicas y pedagógicas le permitían a Bakoš estimular el trabajo de diferentes exploradores eslovacos en varias disciplinas (versología o métrica histórica comparada, genología, teoría de la comunicación literaria, estudio sistemático de las llamadas formaciones estilísticas, etc.). Por fin, su capacidad de analizar, definir y generalizar, según los principios de poética histórica, le llevó a la voluntad de rehabilitar, en cierta medida, los conceptos tradicionales de literatura y de conciliarlos con los frutos recientes del arte y de la literatura moderna. A pesar de lo difícil de esa simbiosis hay que volver a destacar su empresa fenomenal.

Ahora bien, a medida que crecía el deseo de ofrecer un nuevo instrumento metódico bien premeditado, se resforzaba el deseo de un regreso a los horizontes siempre vigentes de la historia y crítica literaria. El impulso decisivo era un desarrollo innovador del arte moderno, el afán de varios escritores europeos y mundiales de crear una visión universal de la realidad. Sin omitir nada de lo que se nutrían las raíces auténticas de la literatura nacional. Y era precisamente el terreno académico que desempeñaba en esos aspectos por aquel entonces un papel primordial. Consistía en la posiblidad de buscar nuevos caminos para poder vincular lo teórico a lo histórico y a la vez crítico, de la investigación literaria.

Uno de los ejemplos destacados que cumplía completamente con tal ideal era la figura de Jozef Felix. Bien que su actividad multifacética se desenvolvía ya en la época de entre dos guerras, su criticismo, ante todo en el área de literaturas romances, junto con el conocimiento profundo de la literatura eslovaca, respondía plenamente a un anhelo simbiótico. 
Hay que decir que en Eslovaquia la tarea del crítico literario se ve, de costumbre, acompañada por su labor traductora y pedagógica. Así se se puede realizar de modo más eficiente el papel educativo o instructivode la enseñanza universitaria. En el caso de Felix, autor de muchos epílogos a obras traducidas, sobre todo de literatura francesa, así como de estudios críticos y analíticos se trataba, en primer plano, de ofrecer un modelo sólido que hubiera podido corrigir hasta ciertas limitaciones de la literatura eslovaca, inmersa en varios aspectos en el provincialismo creativo. Toto eso era válido tanto para el campo pedagógico como el crítico y el histórico, ante todo con el fin de formar a nuevos adeptos jóvenes de similar orientación, incluso para su praxis traductora. No es inútil recordar que los orígenes de esa labor crítica, interdisciplinaria o pluridimensional, siguen desarrollándose en Eslovaquia hasta hoy día, por destacar el sentido mismo de mediación cultural y valorar, a la vez, el nivel estilístico de las traducciones eslovacas. Lo que atestigua la otorgación anual del Premio Ján Hollý por traducción literaria, del Premio Matej Bel por traducción especializada, sin omitir el papel parecido de Universiadas de traducción destinadas para los jóvenes estudiantes universitarios.

Como se ve, lo pluridimensional de esas actividades encuentra en Eslovaquia, desde los años 60 hasta hoy día, buen número de gratos y ambiciosos seguidores.

Una rama no menos significativa, bien que hoy día un tanto desdeňada, está representada por la obra teórica de Dionýz Ďurišin a quién he dedicado el interés más detallado en uno de los números de Interlitteraria bajo el título Dos personalidades de la comparatística (Claudio Guillén, Dionýz Ďurišin) (Franek 2014). Me di cuenta de que los dos teóricos comparten en varios aspectos una posición análoga. Se refiere ante todo al término tan ardiente „influencia“ sometido en ambos casos a una visión dialéctica, por incorporar en dada visión la unión de lo nacional y supranacional o bien, en Ďurišin, de la literatura nacional y la literatura mundial. Si, por una parte, esa unión está edificada, en Guillén y con acento marcado, sobre el modelo histórico, crítico y teórico, en Ďurišin se nota, bajo los impulsos de poética histórica de Bakoš, una posición científica, siendo fruto de los estudios intralitarios. Así que hablando de las leyes evolutivas de la literatura nacional pone de relieve Ďurišin existencia de las llamadas líneas evolutivas de diferentes literaturas nacionales en el diálogo cultural.

Al salir do lo anteriormente dicho, la concepción del comparatista espaňol sa aproxima, por definición, más a bien al concepto cultivado por Jozef Felix. De todos modos, bajo la óptica de esas interacciones no se puede menospreciar tampoco la tesis primordial de Ďurišin según quien la mediación cultural concede lugar principal al papel decisivo o determinante de la literatura 
receptora, nacional. De esa manera Ďurišin ha logrado corrigir o hasta desmentir muchas tesis de los comparatistas occidentales (P. van Tieghem, A. J. Rousseau, p.j.) que salían en sus teorías de la influencia causal y hegemónica de las llamadas literaturas grandes en las pequeňas. Cuando observo, por una parte, debida a esas tesis, cierta oposición a los argumentos de Felix, por otra parte, no se puede perder de vista en mi juicio una significación notable de la concepción del eminente crítico eslovaco quién destacaba a cada momento el término de la universalidad de literaturas nacionales, a partir de lo más valioso que ésas, por criterios severos y auténticos, representan para el enriquecimiento del diálogo cultural.

Es natural que la lista de los críticos eslovacos hubiera sido más larga, por mencionar al menos a Blahoslav Hečko (véanse el libro Aventuras de la traducción, Hečko 1991) quien, como traductor copioso y valioso de literaturas italiana y francesa, en sus estudios ensayísticos y críticos hacía resaltar una riqueza ilimitada del lenguaje eslovaco, de la riqueza de su uso metafórico y coloquial siempre vivo, en la búsqueda estilística de los equivalentes apropiados.

Pues no es sorprendente que en varios modelos teóricos y analíticos se manifieste en Eslovaquia en esa época una tendencia marcada hacia una síntesis artístico-científica. Por cierto, siempre nos movemos en el espacio propiamente literario lo cual, sin omitir contextos exteriores de la obra literaria, caracteriza casi todos los accesos eslovacos. Su definición más o menos nítida aparece en la unión de lo sincrónico y lo diacrónico, por los descubrimientos nuevos observados asimismo en la versología y la teoría de la comunicación. Acaso no sería erróneo constatar que en ese contexto predominara, sobre todo al final de los años 60, años realmente fructíferos, el concepto simbiótico de Anton Popovič. Su método parece a primera vista bastante tradicional, mimético (estudio histórico acompañado con lo temático, sociocultural o biográfico de literaturas comparadas). Naturalmente, sobre el fondo del proyecto sintético de Popovič sobrevivía todavía una marcada dosis de subjetividad y de fervor emocional, típico del convívio interno con la literatura y con la producción traductora de los escritores eslovacos y extranjeros. Podemos observarlo en el libro La traducción y la expresión (1968) orientado a la recepción eslovaca de los autores rusos de índole romántica y realista y a su influencia en la literatura eslovaca. El intento de Popovič era pues literario y, a la vez, cultural en el sentido amplio de la palabra.

Como sucesor y discípulo de la teoría estructural y linguística del checo Jiří Levý, junto con las lecciones teóricas tomadas de Bakoš, se esforzaba Popovič ante todo por cumplir el ideal de una mediación, personalmente auténtica y „resentida“, en el proceso de la interacción literaria. En el tratamiento de los aspectos versológicos se refleja, al mismo tiempo, su aptitud interior gracias 
a lo cual el conocimiento normativo del verso se ve enriquecido por una percepción individual, erudita, „revivida“ e interiorizada. Por brevedad de mi contribución no sería posible aducir también buen número de otros versólogos eslovacos quienes en el pasado (V. Kochol, V. Turčány, F. Štraus, p. j.) y en el presente (J. Zambor) demuestran una variada gama de accesos sintéticos o multidisciplinares.

La coexistencia de varios modelos eslovacos de comparación versológica atestigua una tendencia clara a los horizontes interliterarios. Por la unión de lo teórico y lo empírico es posible abandonar, en cierta medida, los postulados objetivistas de la poética histórica. Los aspectos estructurales y formales de la poesía se vinculan así a la necesidad de un entorno a la tradición, a las raíces simbólicas o espirituales de la existencia humana. Bien que los principios de la poética constituyen una fase preparatoria, teórica para el análisis versal, pueden verse demasiado unilaterales ya que no permiten abrazar de un modo vivo o revivido la naturaleza originaria del acto poético, en relación auténtica con la historia de una nación y de su identidad cultural. Por eso hay que considerar esas tendencias unificadoras y diferenciadoras de los tratadistas eslovacos en aquella época como una plataforma útil para conseguir una síntesis artísticocientífica. El papel comparativo de la investigación en el área de relaciones interliterarias ha encontrado el partenario orgánico en una actitud históricocrítica, como trataba de proponerlo Claudio Guillén (véase Entre lo uno y lo diverso. La Literatura Comparada (Ayer y hoy); la última edición es de 2005). Pero en Eslovaquia, frente al proyecto español, la literatura comparada no existía como una disciplina autónoma con sus propias leyes y criterios. Lo importante era considerar en primer lugar les necesidades de la literatura eslovaca. A pesar de qué algunas de las premisas eslovacas documentan varios puntos comunes con la teoría del comparatista español . Por lo demás, esa señal simbiótica no se limitaba a los objetivos meramente académicos sino que intervenían en el proceso educativo en algunas universidades eslovacas (El gabinete de la comunicación literaria en Nitra).

En cuanto a mi propio trabajo comparativo, he querido extenderlo, por mi formación universitaria (estudio filológico y pedagógico de dos idiomas el francés y el español) sobre el área de relaciones literarias entre Francia y Eslovaquia en la época de entre dos guerras. Mi proyecto, guiado en la academia por mi maestro J. Felix, llevaba el título El estilo de la traducción. Análisis teórico-evolutivo y crítico de las traducciones eslovacas de Paul Claudel (fue finalizado ya en 1975 pero por intervención exterior de la llamada normalización ideológica no fue editado hasta 1997). El primer impulso era inevitablemente normativo para que se puedan explotar ampliamente los reparos preciosos de mi predecesor Bakoš, reparos que podían satisfacer 
exhaustivamante varias exigencias metódicas relativas al horizonte evolutivo del verso eslovaco. Por necesidad paralela fue necesario tomar en consideración también la evolución aparentemente similar del verso francés. Al emprender esa batalla, efectivamente una batalla muy dura en el plano metódico y personal, intentaba penetrar en el núcleo conceptual de diferentes teorías sobre el verso francés (de M. Grammont, P. Guiraud, J. Cohen o H. Meschonnic). En esa línea debo añadir que el finalizar mi estudio, después de tantas dudas y hesitaciones, apareció como más relevante una imagen sintética de la poesía y poética neosimbólica del escritor francés. Al apropiarme gradualmente su visión universal, presente ante todo en su obra Art poétique, junto con todo un conjunto de aspectos literarios y extraliterarios, me familiaricé con el núcleo oculto, difícil de descifrar, de su cosmovisión. Llegué, en definitava, a aprender que el instrumento principal de la visión poética está encarnado en el concepto de la metáfora general que sirve para descubrir esencia simbólica y espiritual de la existencia humana o una conjunción de las cosas visible e invisibles en el acto de hacer poesía. Y no era por azar que, gracias a esa revelación, surgió ante mí el papel unificador de todos los componentes del ritmo siendo, por definición, estéticamente válido para cada poema.

Desde esas perspectivas se vio natural seguir en primer lugar la cadena fónica o melodiosa del verso francés y compararla al verso de las traducciones eslovacas. Un subjetivo convivir con lo específico de sistemas diferentes de versificación se unía, pues, a la observación de las propiedades rítmicas típicas, al mismo tiempo, de la poesía misma de nuestros poetas-traductores (E. Boleslav Lukáč, P. Gašparovič Hlbina, Ján Haranta, K. Strmeň) que entraron contacto con el verset bíblico, relativamente libre, claudeliano. Por consiguiente, en el proceso de la comparación una de las preguntas se refería al valor estético de las translaciones eslovacas en las diversas épocas de su creación. Al hacerlo, el criterio crítico y valorativo era para mí, hasta qué punto nuestros poetas sabían responder a las exigencias semántico-fónicas del verso original y, de modo independiente, qué cualidades tenían esos versos respecto al principio de su homogeneidad estética. Pues mi comparación tenía que ser tanto subjetiva, en relación con la poética francesa silábica de Claudel, como objetiva, con respecto a lo normativo de variables formas silabotónicas (el yambo, el troqueo, el dactilo-troqueo) empleadas en la poesía eslovaca en las etapas respectivas de su evolución.

En la primera fase de mi investigación, analizando los primeros versos de Claudel traducidos en Eslovaquia por E. Boleslav Lukáč, he acabado de constatar la función preponderante del metro yámbico. Ya M. Bakoš había observado que la realización métrica de ese verso enfático pero muy bello y original debe ser regular reflejando así una clara dependencia de las reglas 
métricas empleadas desde el comienzo del siglo 20 por la generación romántica y parnasiana, representada ante todo por eminentes poetas Pavol Országh Hviezdoslav y Štefan Krčméry. Pue ese factor rítmico debía producir, por su naturaleza específica, numerosos cambios en la construción semántica y sintáctica de los versos traducidos. El resultado era que en la concepción de ese traductor más asiduo de la poesía claudeliana en Eslovaquia, sobre todo del gran poema Le chemin de la Croix (1924, 1929, 1948, 1949), aparecieron varios desvíos del original: la expresividad metafórica, el tono elevado o enfático acompañado con abundancia de palabras coloquiales, singulares o de licencias verbales. Tanto más que todos esos rasgos estilísticos se oponían, en general, al vocabulario más neutral, más moderado del verso claudeliano. Al observar más detenidamente, por una óptica dialéctica, el carácter genérico de los versos, sobre todo en la interpretación del verso épico del poeta francés (Magnificat), me di cuenta de que Lukáč no ha podido conseguir la deseada homogeneidad estética del verso. Por el contrario, sus procedimientos eran admirablemente congeniales en contacto con la naturaleza lírica y tradicional del poema Kyrie Eleison.

Tal estudio comparativo conduce al final a un descumbrimiento significativo acerca de lo desigual en el desarrollo de ambas literaturas, francesa y eslovaca. Lo reparé asimismo en otras traducciones eslovacas hechas posteriormente y situadas más cerca de la poética de Claudel. Bien que en las traducciones de nuestro poeta simbólico P. Gašparovič Hlbina (véase el poema Saint-Paul, 1943), se realiza el nuevo modelo métrico, dactilo-trocaico con su moderación semántica y pureza idiomática. El análisis demostró que esa cualidad esencial fue fielmente reproducida (el poema Gloria, 1943) por el „verdadero“ verso libre de K. Strmeň. Ese poeta eslovaco ha sabido lograr el mismo efecto más tarde en la traducción del poema Le chemin de la Croix (1954) así como de la obra maestra de Claudel, el drama Le soulier du satin.

Pues a través de esas observaciones apoyándose en el decisivo papel rítmico en la poesía llegué a una observación general. Reside no solamente en lo propiamente literario sino en los horizontes amplios de diferencias culturales o mentales entre ambas naciones.

En ese momento pienso volver, al menos parcialmente, al hecho de diferentes sistemas de versificación que funcionan en cada literatura nacional. En la poesía eslovaca, sobre todo en el pasado, predomina el factor obligatorio de la organización métrica. Se trata en mi juicio del factor realmente primordial porque al observar la estructura versal en su totalidad, en relación con otros elementos (silábicos, estróficos, tropológicos o figurativos), se percibe que la naturaleza particular del acento métrico representa casi en todas las literaturas nacionales el único rasgo realmente distintivo. Pues no nos sorprende que 
en el caso de la traducción poética hay que considerar ese hecho como una dura piedra de toque cuya solución exige, por cierto, una preparación atenta y detallada. Es natural que ese problema se encuentre, a la vez, en el centro de interés de varios teóricos. En el verso francés, también en consonancia con la percepción de Claudel (véase Réflexions sur la poésie (1928), Claudel 1954), el acento métrico está colocado en la última sílaba de un segmento sintáctico $\mathrm{u}$ oracional del verso. Pues el conocimiento teórico general sirve para distinguir más claramente la posición del acento métrico en la estructura versal. Se puede destacar la validez de ese conocimiento para el análisis de traducciones poéticas a otros idiomas lo cual exige observar una interdependencia de todos los componentes, sea semánticos sea sintácticos o fónicos. Volvamos a subrayar que al seguir la evolución del verso con sus permanentes cambios, el mismo fenómeno se produce en la cadena rítmica de cada verso nacional.

Pero hay, además, otro problema. Es que a diferencia del interés objetivista de $\mathrm{M}$. Bakoš ése estriba en la percepción interiorizada de la naturaleza acústica de la poesía bien que esa percepción no se aleja marcadamente de la observación de las reglas codificadas de acentuación. Lo que prueban según otro tradatista y poeta eslovaco Štefan Krčméry posibles cambios de acentuación en la estructura métrica del verso, pero sin negar esencialmente la regla general sobre la regularidad yámbica. Recordemos que dada concepción, más subjetiva, proviene de la naturaleza musical del ritmo poético (el poeta mejicano Octavio Paz sostiene con razón que el sentido es el hijo del sonido). Así como lo mostraron varios estudios míos, ese factor puede vincularse al estudio simbólico, figurativo y metafórico que refleja una actitud espiritual y ética del poeta, en relación con su entorno natural y social. La visión intrínseca lleva en sí la garantía de que la creación literaria no deje de ser humana, saliendo de la unión del escritor con la tierra.

Pues no es nada extraño que T. Navarro Tomás, el conocido experto en métrica castellana (véase Métrica española, Tomás 1968) ha observado en primer lugar las leyes internas de la poesía, derivadas de su musicalidad. Al representar cierto paralelo a nuestro poeta Krčméry ha sentido Navarro Tomás el ritmo como algo que no se puede captar únicamente por vía lógica o racional (de ahí que su concepto no respeta siempre los límites de las palabras españolas pero un conjunto de agrupaciones dactílicas y trocaicas que se parecen por sus deshabitual organización métrica a la poesía popular eslovaca (ejemplo: de sus) /ójos los / huesos fi/jaron).

Ese sistema musical funciona dentro de la acentuación normativa del verso español. Lo importante es saber que la acentuación en el idioma español responde a las reglas gramaticales de pronunciación y difiere, por consiguiente, de la ley eslovaca que prescribe colocar el acento en la primera sílaba de la 
FRANEK

palabra (škola - el troqueo; a on - el yambo). Aunque, como hemos visto, es una ley bastante general que puede ser corrigida por la necesidad de „sentir“ el ritmo y percibir sus varios matices de declamación en la cadena fónica, para explicar también el uso de los pies regulares métricos del yambo (o ó), por ejemplo.

Al seguir la naturaleza prosódica del verso español y eslovaco se nota que sus reglas se apoyan, en general, en el modelo rítmico propuesto por el célebre filólogo y poeta venezolano-chileno Andrés Bello. Me fijé en que su sistema de versificación contiene una variedad de pies métricos correspondientes a la pronunciación española. Frente a la poesía eslovaca se percibe el uso más frecuente de los pies anfibráquicos y anapésticos (habló, engendró) y, menos, los dactílicos, yámbicos o trocáicos. Se trata de formas variables, silábicas y silabotónicas, del idioma español, formas del conocido „endecasílabo“, de „rimas“, por ejemplo, con acentuación regular. Por eso existe una variada concepción rítmica de los tratadistas españoles (J. Domínguez Caparrós. A. Quilis, R. de Balbín y otros) que subrayan una irregularidad acentual de la poesía española. Casi todos ellos podrían sostener que, a diferencia de formas canonizadas del yambo eslovaco, la naturaleza misma de la acentuación española, según normas vigentes en ese idioma, no soporta similar regularidad métrica (Domínguez Caparrós dice que en el verso español es imposible ver tal „amontonamiento“ de los acentos). Por comparación de ambos versos, el eslovaco y el español, se puede llegar a un descubrimiento esencial: se refiere a la imposibilidad de estudiar tan exactamente por vía estadística como lo hacía Bakoš en relación con el verso eslovaco (la escuela aristocrática de Hviezdoslav, la escuela popular de Štúr), los rasgos generacionalmente parecidos de la poesía española.

En ese contexto destaca la primera fase de estudios prosódicos o métricos que sean necesarios para la investigación posterior, comparativa. Esos reparos salen de las bases generales o universales que son privativos de la labor misma de un comparatista. Posibilitan, al mismo tiempo, valorar con más seguridad el nivel de creación y de re-creación individual de un poeta -traductor y su posición en las coordonadas históricas de de su propia cultura nacional. Pues esa actividad interdisciplinaria, por un movimiento aparentemente inverso, trata de respetar plenamente variedad multiforme de las obras de diferentes literaturas nacionales y su carácter especial.

Pienso que esos deseos ontológicos no los podemas, ni siquiera hoy día, ignorar. Pues son verdaderamente preciosos asimismo por su afán pedagógico de educar. Educar con el fin generoso, éticamente apoyado para crear una imagen siempre viva de una variada identidad cultural. 
A pesar de que, se sabe bien, los fines pragmáticos de nuestros tiempos ponen muchos obstáculos a ese proyecto, estoy convencido de que esos anhelos por vía de conocimiento y autoconocimiento - vuelven a encontrar sendas libres de un desarrollo natural. Tanto más que seguirán siendo nutridas de un tesoro irreamplazable de la literatura, de sus horizontes ilimitados y, a la vez, bien delimitados por un techo protector y defensivo, simbólico, simbiótico y espiritual (véase Talvet 2009). Mediante una intuición sabia podemos creer que gracias a los valores emocionales e intelectuales de un ser relexivo e imaginativo, esos valores originales y universales van en el porvenir a perdurar.

\section{Comparative versological research in Slovakia}

A selection of representatives and concepts from the 1960s and 1970s

Mikuláš Bakoš (1914-1972). Literary scholar, philosopher of aesthetics, university professor, translator of literary theory from Russian. Founded Institute of World Literature and Languages in Bratislava (1964). His theoretical thinking was based on Russian formalism (V. Shklovsky, V. Zhirmunsky, B. Tomashevsky and others) and on the methods of Czech scholar Jan Mukarovsky. In his book The Evolution of Slovak Verse from the Stúr School (1939, 1949, 1966) he worked with the legacy of Slovak versology (T. Milkin, Š. Krčméry) and through an integral analysis of the components of poetic structure (sound, syntax, intonation, semantics and euphony) he tried to capture the evolution of modern Slovak poetry. In 1941 he published a selection of essays on Russian formalism titled Theory of Literature, focused on internal rules of the literary process and literary structure. In the 1960s, on the basis of inter-linking literary theory and historical verse metre, he proposed the possibility of the symbiosis of avant-garde and traditional historical views of literature. He led a team of scholars in the areas of versology, comparative literature and genealogy. This research was interrupted by political censorship in the early 1970s. His other significant monographs are: Avant-garde, 1938, Literary History and Historical Poetics, 1973.

Jozef Felix (1913-1977). Literary critic and historian, literary translator from Romance languages, critic of literary translation, university professor, editor. Translator of Villon's The Great Testament, as well as works from Romance languages (by Molière, Valéry, Camus, Cervantes, Unamuno - over 50 translations) that he accompanied with his afterwords, commentaries and scholarly articles that provided contextual information. He worked with detailed historical-theoretical analysis of textual interpretation. His critical articles on Slovak literature and literary translation focused on the need to 
FRANEK

liberate it from the provincial isolation of Slovak literature and come closer to the universal mission of world literature. As a scholar of versology he collaborated with Slovak poets (V. Turčány, J. Smrek) in his poetry translations. His sustained contribution to the evolution of textology, textual criticism and the criticism of translation and editing is invaluable for Slovak literary culture. His students and followers continue to further his legacy. His translations from French focused on religious works similar to some Slovak prose fiction works of the period. Monographs: Roads Towards the Greats 1957, Arlecchino Bent Over Water 1965, Contemporary Modernity 1970, and others.

Anton Popovič (1933-1978). Literary theorist and historian, university professor, versologist and comparatist. His initial subject of research were Slovak-Russian literary relationships, which he analyzed in his work Translation and Expression (1968), focusing on the influence of Russian romantic and realist authors on Slovak literature. With a view to the work of Bakoš and Durišin he also contributed to the theory of literary communication. Key in this area is his contribution to comparative versology, in which he synthetically applied his own subjective view of the verse in the context of all its components. The textological aspect of his research was organically connected to a wider literary-historical context (socio-political, psychological, cultural, biographical, etc.). From the 1970s became the most important Slovak theorist of literary translation. In the last years of his life he led the Cabinet of Literary Communication in Nitra. Monographs: Poetics of Literary Translation, 1971, Structuralism in Slovakia, 1970, and many others.

Dionýz Ďurišin (1929-1997). Literary theorist and comparatist. Author of works on theory and history of comparative literature and interliterary relations (Slovak Realist Short Story and N. Gogol, 1966), based on the findings of Russian formalism that he knew from M. Bakoš. He emphasized the concept of the evolutionary developmental series of national literature. His most significant contribution is in his focus on typology, in contrast to the dominant genetic paradigm of the Spanish comparatist C. Guillén. His term supranationality, which he considered to be a natural part of comparative research, has become well-known. In this context is also important his dialectical understanding of "influence", while he emphasized the decisive position of the receiving context of national literature, with a view to the developmental patterns. In the 1980s he developed his theory of interliterary communities, which he categorized according to the specific characteristics of the coexistence of national literatures. Monographs: Theory of Comparative Literature, 1970, On Literary Relations, 1975; as well as many essays on interliterary communities.

Ladislav Franek (1947). Literary historian and theorist, comparatist, critic of literary translation, university professor, translator from Romance languages. 
His theoretical-historical scholarly work was inspired by the work of Bakoš, Felix, Popovič. As a Romance literatures scholar, Franek focused on European and world modernism (O. Paz, F. Pessoa, P. Claudel, compare Modernism in Romance Literatures 2005). He emphasized their universal meaning and synthetic view of the world. Along these lines he has widely translated from French (P. Claudel, G. Flaubert), Spanish (J. Goytisolo, J. Lezama Lima, J. Ramón Jiménez) and Portuguese (J. Guimarães Rosa, O. Lins). His eclectic research is reflected in his work The Style of Translation. Evolutionary-theoretical and Critical Analysis of Slovak Translations of Paul Claudel,1997; finished already in 1975). This structuralist analysis was based on a number of Slovak and foreign sources (J. Cohen, M. Grammont, P. Guiraud) with a view to the symbolic-universalist character of Claudel's poetics. The findings were later used in the confrontation of Slovak and Spanish verse metre. In his teaching he focuses especially on the works of the so-called boom in Latin American literature. Other monographs: Interdisciplinarity in the Symbiosis of Literary Studies and Art, I. 2012, II. 2016).

\author{
Ladislav Franek \\ Ladislav.Franek@savba.sk \\ 82107 Bratislava \\ Čiližská 10 \\ SLOVENSKO / SLOVENIA
}

\title{
Referencias
}

Bakoš, M. 1968. Vývin slovenského verša od školy Štúrovej. Bratislava: VSAV.

Bakoš, M. 1969. Literárna história a historická poetika. Bratislava: Ústav svetovej literatúry a jazykov SAV.

Bělič, O. 1975. En busca del verso español, Praha: Universitatis Carolinae, Philologica monographia.

Claudel, P. 1926. Art poétique, Paris: Mercure de France.

Claudel, P. 1954. Réflexions sur la poésie, Paris: Gallimard.

Domínguez Caparrós, J. 1993. Métrica española, Madrid: Ed. Síntesis.

Guillén, C. 2005. Entre lo uno y lo diverso. La Literatura Comparada (Ayer y hoy), Barcelona: Marginales Tusquets.

Felix, J. 1957. Cesty k vel'kým. Bratislava: Slovenské vydavatel'stvo krásnej literatúry.

Felix, J. 1962. Hugov Satyr v slovenčine. Bratislava: Slovenské pohlady, 78, č. 6, s. 64-70.

Felix, J. 1970. Modernita súčasnosti. Bratislava: Slovenský spisovatel'.

Franek, L. 1997. Štýl prekladu. Vývinovo-teoretická a kritická analýza slovenských prekladov Paula Claudela. Bratislava: Veda, vydavatel'stvo SAV. 
FRANEK

Franek, L. 2005. Modernita románskych literatúr. Bratislava: Veda.

Franek, L. 2012. Interdisciplinárnost' v symbióze literárnej vedy a umenia. Bratislava: Veda.

Franek, L. 2014. Two Personalities of Comparative Literary Studies. - Interlitteraria, $19 / 2,244-260$.

Franek, L. 2016. Interdisciplinárnost'v symbióze literárnej vedy a umenia II. Bratislava: Veda, vydavatel'stvo SAV.

Jozef Felix (1913-1977) a cesta k modernej slovenskej romanistike. 2014. Bratislava: Veda, vydavatel'stvo SAV.

Levý, J. 1963. Umění překladu. Praha: Československý spisovatel.

Mikuláš Bakoš a moderná literárna veda. 2016. Nitra: Univerzita Konštantína Filozofa.

Mukařovský, J. 1948. Kapitoly z estetiky I. Praha: Svoboda.

Mukařovský, J. 1995. Básnická sémantika. Praha: Carolinum-Univerzita Karlova.

Navarro Tomás, T. 1968. Métrica española. Reseña histórica y descriptiva, La Habana: Instituto del Libro.

Paz, O. 1983. Sombras de obras, Barcelona: Biblioteca del bolsillo.

Paz, O. 1993. El laberinto de la soledad, Madrid: Ed. Cátedra.

Popovič, A. 1968. Preklad a výraz. Bratislava: SAV.

Quilis, A. 1994. Métrica española. Barcelona: Ariel.

Talvet, J. 2009. El enfoque simbiótico de la cultura postmoderna. Granada: Comares. 